\title{
Introduction to Doctoral Symposium
}

The ASE Doctoral Symposium is a one day forum that seeks to bring together PhD students working on foundations, techniques, tools and applications of automated software engineering and give them the opportunity to present and to discuss their research with researchers in the ASE community in a constructive atmosphere. Specifically, the symposium aims to provide a setting whereby students receive feedback on their research and guidance on future directions from a broad group of advisors, foster a supportive community of scholars and a spirit of collaborative research, and contribute to the conference goals through interaction with other researchers and conference events

The symposium is intended for students who have not yet completed their dissertation research and do not expect to write up their dissertation before the conference. This year six students were selected to present their work. Their extended abstracts are published in these proceedings.

We would like to thank the Doctoral Symposium Committee, John Penix, Perry Alexander, Elisabetta Di Nitto, Michal Young, and Mats Heimdahl for their help in providing feedback to all the students who submitted to the Doctoral Symposium and for participating in the Doctoral Symposium Panel.

Steve Easterbrook

Doctoral Symposium Co-Chair
Sebastian Uchitel

Doctoral Symposium Co-Chair 